\title{
Effectiveness of EMG use in pedicle screw placement for thoracic spinal deformities
}

\author{
Authors Ali Öner ${ }^{1}$, Claire G Ely², Jeffrey T Hermsmeyer², Daniel C Norvell ${ }^{2}$ \\ Institutions ${ }^{1}$ Orthopedics and Traumatology Department, Mus State Hospital, Mus, Turkey \\ ${ }^{2}$ Spectrum Research Inc, Tacoma, WA, USA
}

\section{ABSTRACT}

Study design: Systematic review.

Objective: To determine the effectiveness of using electromyography (EMG) during intraoperative pedicle screw placement in patients with thoracic deformity.

Methods: A systematic review of the English-language literature was undertaken for articles published between 1970 and July 2011. For our first question, we identified all articles that were designed to evaluate the diagnostic test characteristics (ie, measures of validity such as sensitivity, specificity, positive predictive value [PPV], negative predictive value [NPV]) of EMG for thoracic deformities in adolescent and adult patients. For our second question, we attempted to identify all articles that reported complication rates (pedicle wall breach or new neurological event) after pedicle screw placement in the same population comparing patients who did and did not undergo intraoperative EMG. Articles were excluded if they did not report or give raw data to calculate at least one of the four primary diagnostic test characteristics: sensitivity, specificity, PPV, or NPV for study question one. Articles were excluded if they did not have a "no EMG" control group for study question two. Other exclusions were reviews, editorials, case reports, non-English written studies, and animal studies. We rated the overall body of evidence with respect to each key question using a modified Grades of Recommendation Assessment, Development and Evaluation (GRADE) system for diagnostic and therapeutic studies.

Results: The overall strength of evidence evaluating the diagnostic characteristics was low due to inconsistent findings between studies and uncertainty of the impact of false-negatives. The fairly low sensitivity may lead to a high-false negative rate. It is unclear what the impact of false-negatives would be since no neurological injuries were identified in the studies summarized. A higher specificity would suggest a fairly low false-positive rate; however, the rates could be as high as $30 \%$. If sudden changes in treatment are required in the absence of any adverse event, this could be considered a limitation of such testing. The overall strength of evidence for evaluating the efficacy of EMG compared with no EMG was insufficient because of literature shortage on this topic.

Conclusion: The overall strength of evidence evaluating the diagnostic characteristics was low due to inconsistent findings between studies and uncertainty of the impact of false-negatives. Given the low sensitivity and potential high rate of false-negatives, pedicle wall breaches may occur, without EMG notification. These undetected breaches may lead to loose or weak screw position which may lead to neurovascular complications during or after a translation-rotation maneuver, especially in rigid deformities. The higher sensitivity would suggest a lower rate of false-positives. We recommend considering the use of intraoperative EMG-monitoring method to help identify potential complications based upon available technology, personal experiences and preferences; however, surgeons should keep in mind that false-positive results may lead to increased surgery time and increased blood loss. The surgeon should not depend solely on EMG since it can also render false-negatives.

This systematic review was funded by AOSpine. 


\section{STUDY RATIONALE AND CONTEXT}

The correction of spinal deformity is a challenge for the spine surgeon. Although pedicle screw construct has been widely accepted as the choice of instrumentation for the correction of spinal deformities, some surgeons avoid using pedicle screws in the thoracic region for spinal deformities because of the rotation and unique anatomy of the thoracic spine that may lead to neural and vascular injury. Due to the potential risk of injury to neural and vascular structures, different methods (anatomical landmarks, intraoperative monitoring, etc) have been developed to guide the surgeon to increase the accuracy of pedicle screw placement [1]. Intraoperative electromyography (EMG) testing is a method used more frequently in the last decade. However, EMG monitoring is still in progress as is reflected in the variable results reported in the literature [2]. To our knowledge, no systematic review has been performed to evaluate intraoperative EMG for thoracic deformities. The primary purpose of this systematic review was to review the efficacy of intraoperative EMG monitoring in patients with thoracic deformity.

\section{OBJECTIVES}

For adolescent and adult patients undergoing pedicle screw placement for thoracic deformity, what are the diagnostic characteristics (ie, sensitivity, specificity, positive predictive value [PPV], negative predictive value [NPV]) of using EMG to identify misplacement? For adolescent and adult patients undergoing pedicle screw placement for thoracic deformity, does intraoperative EMG reduce the rate of a new or worsening neurological event or pedicle wall breach compared with no EMG?

\section{MATERIALS AND METHODS}

Study design: Systematic review.

\section{SAMPLING}

Search: PubMed, Cochrane Collaboration Database and bibliographies of key articles.

Dates searched: 1970 to July 2011.

Common inclusion criteria for both questions: (1) Corrective surgery for deformity; (2) thoracic spine; (3) adults and adolescents; (4) EMG.

Inclusion criteria for question 1: (1) Reference standard: pedicle wall breach, violation, perforation, or penetration; new or worsening neurological deficit; (2) sensitivity, specificity, PPV, NPV.

Inclusion criteria for question 2: (1) EMG versus no EMG; (2) pedicle wall breach; and (3) new or worsening neurological event.

Common exclusion criteria for both questions: (1) $>20 \%$ of population including non-deformity (stenosis, trauma, fracture, degenerative conditions, tumor, and/or infection); (2) lumbar or cervical spine only; and (3) cadaver or non-human studies.

Exclusion criteria for question 1: (1) No reference standard; (2) no report of sensitivity, specificity, PPV, or NPV or lack of raw data to calculate these.

Exclusion criteria for question 2: Lack of a no EMG control group.

Analysis: (1) Diagnostic characteristics were reported if stated by authors; otherwise, they were calculated if the raw data was available; (2) rate of pedicle wall breach or new neurological events were reported from each manuscript or calculated from raw data; (3) data was pooled among studies and mean rates of pedicle wall breach or new neurological events and diagnostic characteristics were weighted by study sample size.

Overall strength of evidence: For evaluating the risk of bias in individual diagnostic studies, we rated the level of evidence using the rating scheme developed by the Oxford Centre for Evidence-based Medicine and used with modification by The Journal of Bone and Joint Surgery American. (A more detailed description can be found in the Web Appendix at www.aospine.org/ebsj.) After individual article evaluation, the overall body of evidence with respect to each key question was determined based on modified precepts outlined by the Grades of Recommendation Assessment, Development and Evaluation (GRADE) system. 


\section{RESULTS}

We identified eight studies [1, 3-9] meeting our inclusion criteria for question 1 (Fig 1). All studies reported corrective surgery with the use of pedicle screw performed for thoracic deformity. Reported age populations varied as four studies involved adolescents only $(n=179)[4-6,8]$ one study involved adults only $(\mathrm{n}=7)$ [3], two studies involved both adolescents and adults $(\mathrm{n}=101)[1,9]$ and one study did not report age of patients $(n=50)$ [7]. Studies varied in what they used as a threshold for indicating a high potential for medial pedicle wall breach. Five studies used a threshold level of $<6 \mathrm{~mA}[1,4,5,7,8]$, one used a level of $<7 \mathrm{~mA}$ [9]; one used a level of $<12 \mathrm{~mA}$ [6]; and one used a threshold of $<15 \mathrm{~mA}$ [3]. There was not enough data available to evaluate diagnostic characteristics by threshold level. Details of each study are presented in Tables $\mathbf{1}$ and $\mathbf{2}$. We did not identify any studies to answer our second study question evaluating complication rates during pedicle screw placement for thoracic spinal deformity comparing EMG monitoring with no EMG monitoring.

Rates of pedicle wall breach, medial pedicle wall breach, and new or worsening neurological event

- All eight studies [1, 3-9] reported if there was a pedicle wall breach. The mean pedicle wall breach rate was $11.6 \%$ (range, $0-53.4 \%$ ).

- Seven studies $[1,3,5,6,8,9]$ reported if there was a medial pedicle wall breach. The mean medial pedicle wall breach rate was 5.6\% (range, $0-16.5 \%$ ).

- Seven of eight studies [1, 4, 5, 7-9] reported if there was a new or worsening neurological event. None of these studies reported a neurological event $(0 \%)$.

\section{Diagnostic characteristics}

- All eight studies [1, 3-9] reported the sensitivity of identifying a pedicle wall breach. The weighted mean sensitivity was $55.0 \%$ across studies (range, $0-100 \%$ ).

- Six studies [1, 3, 4-7] reported the specificity. The weighted mean specificity was $82.1 \%$ across studies (range, 70.1-100\%).

- Five studies $[1,3,8]$ reported the PPV. The weighted mean PPV was $36.2 \%$ across studies (range, $21-100 \%$ ).

- Six studies $[1,37]$ reported the NPV. The weighted mean NPV was $93.9 \%$ (range, $75-100 \%$ ).

- The overall strength of evidence evaluating the diagnostic characteristics was low due to inconsistent findings between studies and uncertainty of the impact of false-negatives (Table 3).

- The fairly low sensitivity may lead to a high falsenegative rate. It is unclear what the impact of falsenegatives would be since no neurological injuries were identified in the studies summarized.
- A higher specificity would suggest a fairly low falsepositive rate; however, the rates could be as high as $30 \%$. If sudden changes in treatment are required in the absence of any adverse event, this could be considered a limitation of such testing.

- The overall strength of evidence for evaluating the efficacy of EMG compared with no EMG was insufficient because of literature shortage on this topic (Table 3).

\section{DISCUSSION}

- Intraoperative EMG monitoring for detection of pedicle wall violation has been favored over the last decade.

- The success of EMG depends on the electricity conductivity of the intraoperative environment which hinge on various factors. In addition, there is still no consensus on which technique and which muscles to use, especially for the upper thoracic region [6].

- Our review showed that the weighted mean rate of a pedicle wall breach across studies was relatively low (11.6\%). The $11.6 \%$ includes all four sides of the wall and the tip of the screw, which did not lead to clinically apparent complications in the studies reviewed. More serious medial wall breaches were even more rare $(5.6 \%)$; however, this is still an alarming rate when considering the devastating complications that could occur as a result of a medial wall breach.

- Our review also showed that the sensitivity and PPV for identifying breaches using intraoperative EMG monitoring were relatively low (weighted means of $55 \%$ and $36.2 \%$, respectively).

- The specificity and NPV were higher $(82.1 \%$ and $93.9 \%$, respectively).

- The overall strength of evidence evaluating the diagnostic characteristics was low due to inconsistent findings between studies and uncertainty of the impact of false-negatives.

- We recommend considering the use of intraoperative EMG-monitoring method based on available resources and personal experiences, but not based upon presentday literature, to help prevent potential complications caused by pedicle wall breaches; however, surgeons should keep in mind that false-positive results may lead to increased surgery time and increased blood loss. The surgeon should not depend solely on EMG since it can also give false-negative results. Other measures of identification should be used. 
Table 1 Study question 1: studies assessing the diagnostic characteristics of EMG use in pedicle screw placement for thoracic deformity.*

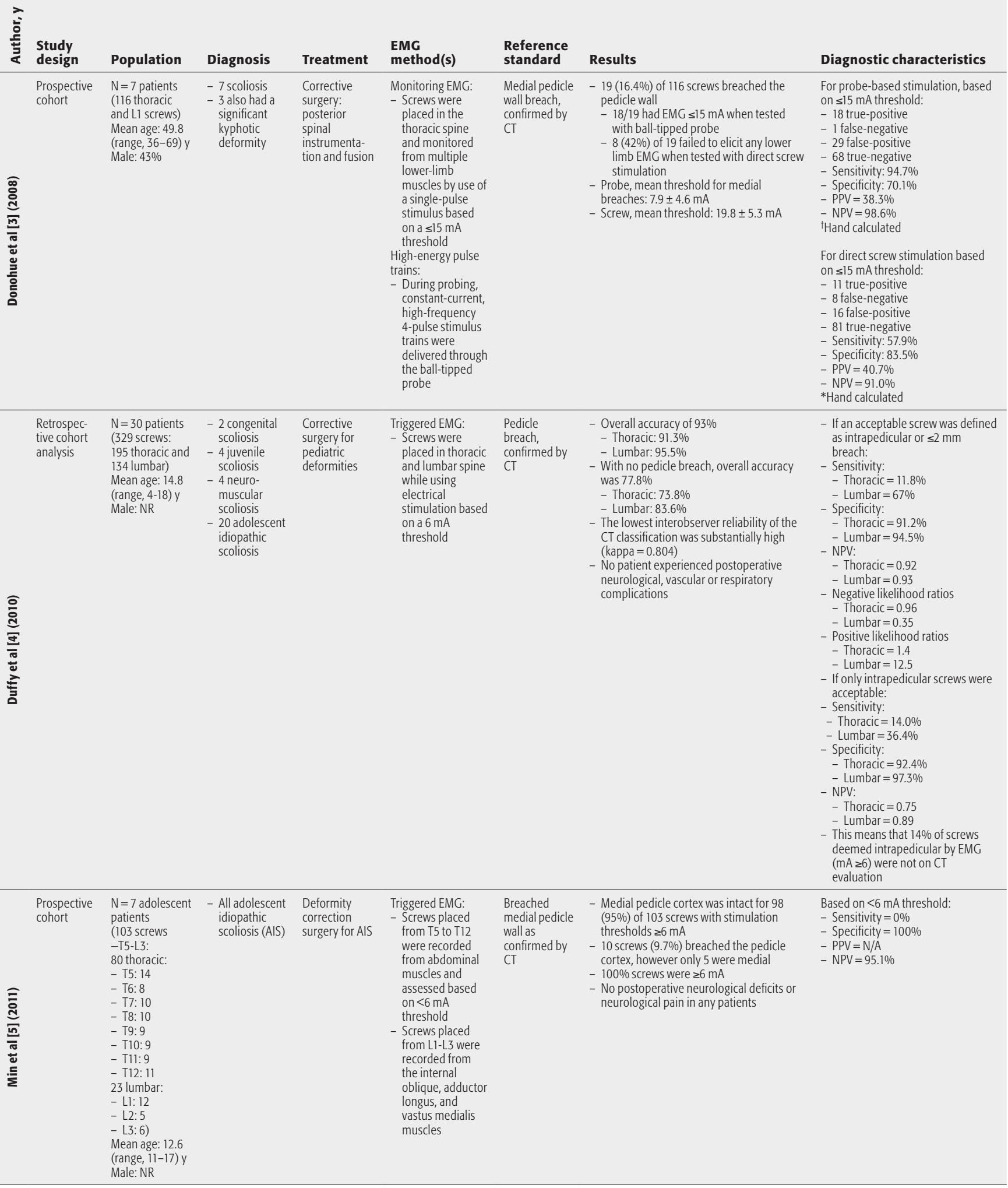


Table 1 (cont) Study question 1: studies assessing the diagnostic characteristics of EMG use in pedicle screw placement for thoracic deformity.*

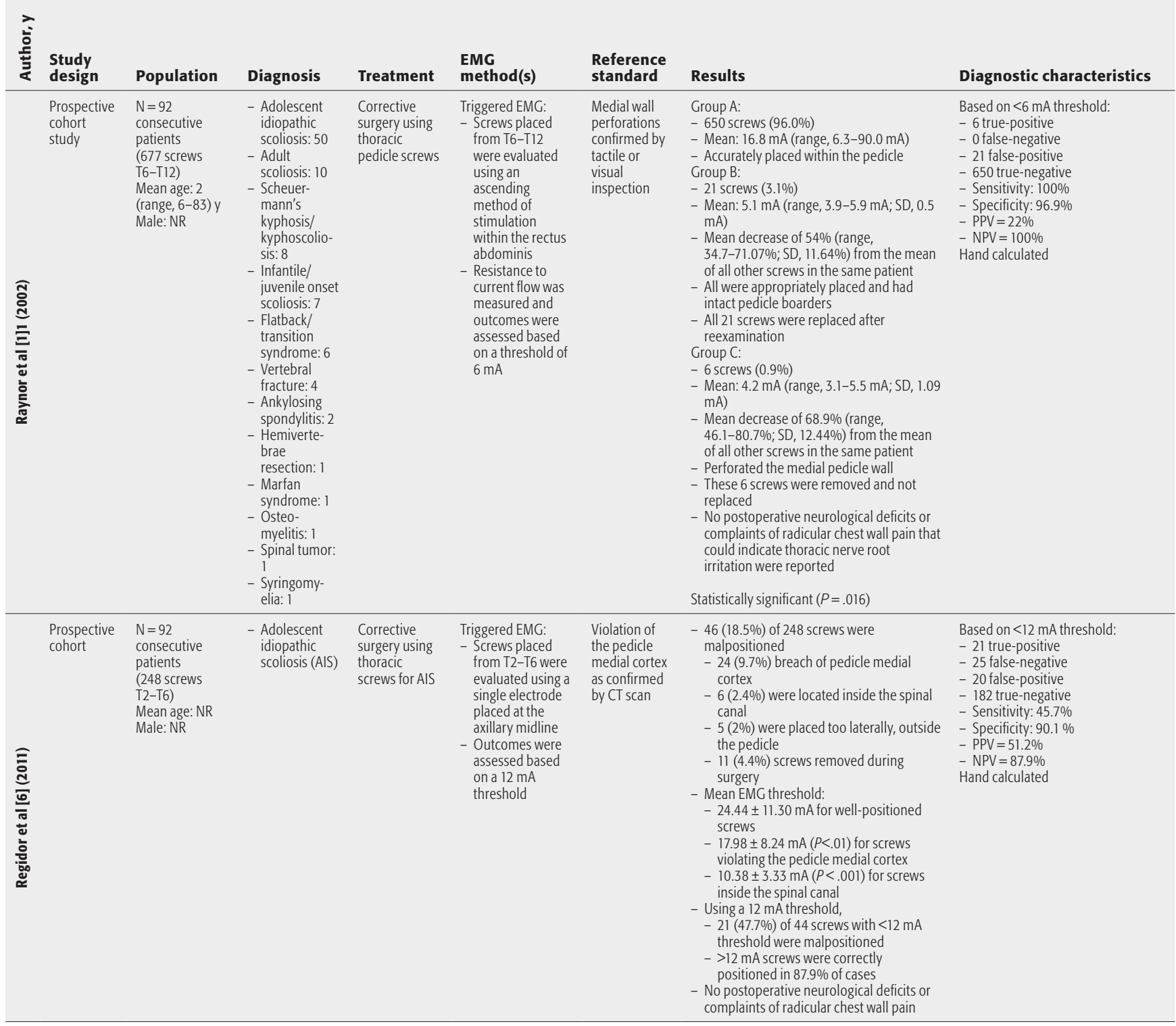


Table 1 (cont) Study question 1: studies assessing the diagnostic characteristics of EMG use in pedicle screw placement for thoracic deformity.*

\begin{tabular}{|c|c|c|c|c|c|c|c|c|}
\hline 产 & $\begin{array}{l}\text { Study } \\
\text { design }\end{array}$ & Population & Diagnosis & Treatment & $\begin{array}{l}\text { EMG } \\
\text { method(s) }\end{array}$ & $\begin{array}{l}\text { Reference } \\
\text { standard }\end{array}$ & Results & Diagnostic characteristics \\
\hline 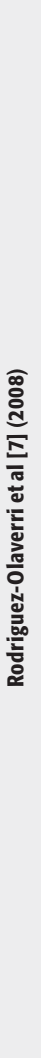 & $\begin{array}{l}\text { Prospective } \\
\text { cohort } \\
\text { study }\end{array}$ & $\begin{array}{l}\mathrm{N}=50 \\
\text { consecutive } \\
\text { patients } \\
\text { (311 screws } \\
\text { T3-T6) } \\
\text { Mean age: NR } \\
\text { Male: NR }\end{array}$ & NR & $\begin{array}{l}\text { Corrective } \\
\text { surgery using } \\
\text { thoracic } \\
\text { screws for } \\
\text { posterior } \\
\text { spinal fusions }\end{array}$ & $\begin{array}{l}\text { Triggered EMG: } \\
\text { - Screws placed } \\
\text { from T3 -T6 were } \\
\text { evaluated using } \\
\text { an ascending } \\
\text { method of } \\
\text { stimulation } \\
\text { within the } \\
\text { intercostals } \\
\text { muscles } \\
\text { - Resistance to } \\
\text { current flow was } \\
\text { measured and } \\
\text { outcomes were } \\
\text { assessed based } \\
\text { on a threshold of } \\
6 \text { mA or a } \\
60-65 \% \\
\text { decrease from } \\
\text { the mean }\end{array}$ & $\begin{array}{l}\text { Cortical } \\
\text { violations } \\
\text { confirmed by } \\
\text { CT and tactile } \\
\text { inspection }\end{array}$ & 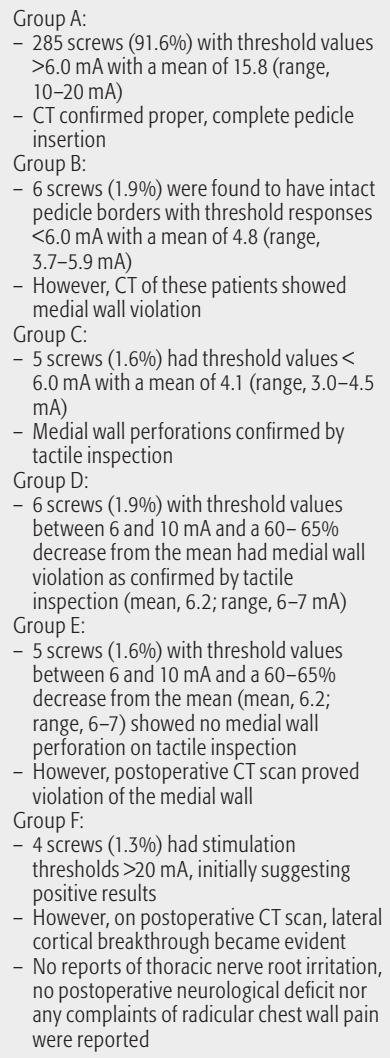 & $\begin{array}{l}\text { Based on }<6 \text { mA threshold: } \\
\text { - } 11 \text { true-positive } \\
\text { - } 15 \text { false-negative } \\
\text { - } 0 \text { false-positive } \\
\text { - } 285 \text { true-negative } \\
\text { - Sensitivity: } 42 \% \\
\text { - Specificity: } 100 \% \\
\text { - PPV }=100 \% \\
\text { - NPV }=95 \% \\
\text { Based on }<6 \text { mA threshold or } \\
60-65 \% \text { decrease from the mean: } \\
\text { - } 22 \text { true-positive } \\
\text { - } 4 \text { false-negative } \\
\text { - } 0 \text { false-positive } \\
\text { - } 285 \text { true-negative } \\
\text { - Sensitivity: } 85 \% \\
\text { - Specificity: } 100 \% \\
\text { - PPV }=100 \% \\
\text { - NPV }=98.6 \% \\
\text { Hand calculated } \\
\text { If diagnostic characteristics were } \\
\text { calculated using a threshold between } \\
6-20 \text { mA and a } 60-65 \% \text { decrease } \\
\text { from the mean, then specificity and } \\
\text { sensitivity would both equal } 100 \%\end{array}$ \\
\hline 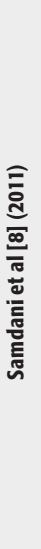 & $\begin{array}{l}\text { Retrospec- } \\
\text { tive cohort } \\
\text { study }\end{array}$ & $\begin{array}{l}\mathrm{N}=50 \\
\text { consecutive } \\
\text { adolescent } \\
\text { patients } \\
\text { (937 screws } \\
\text { T2-T12: } \\
\text { estimate based } \\
\text { on figure: } \\
\text { - T2: } 80 \\
\text { - T3: } 86 \\
\text { - T4: } 74 \\
\text { - T5: } 78 \\
\text { - T6: } 78 \\
\text { - T7: } 84 \\
\text { - T8: } 87 \\
\text { - T9: } 87 \\
\text { - T10: } 89 \\
\text { - T11: } 94 \\
\text { - T12: } 100) \\
\text { Mean age: 14.3 } \\
\text { (range, } 10-20) \text { y } \\
\text { Male: } 18 \%\end{array}$ & - AIS & $\begin{array}{l}\text { Corrective } \\
\text { surgery } \\
\text { involving } \\
\text { posterior } \\
\text { spinal fusions }\end{array}$ & $\begin{array}{l}\text { Triggered EMG: } \\
\text { - Screws placed } \\
\text { from T2-T12 } \\
\text { were evaluated } \\
\text { using stimulation } \\
\text { within the } \\
\text { intercostal and } \\
\text { abdominis rectus } \\
\text { muscles } \\
\text { - Resistance to } \\
\text { current flow } \\
\text { measured and } \\
\text { outcomes } \\
\text { assessed based } \\
\text { on a threshold of } \\
6 \text { mA or a } \geq 65 \% \\
\text { decrease from } \\
\text { the mean }\end{array}$ & $\begin{array}{l}\text { Breach of } \\
\text { cortex as } \\
\text { confirmed by } \\
\text { CT }\end{array}$ & $\begin{array}{l}\text { - } 114(12.2 \%) \text { of } 937 \text { breached the cortex } \\
\text { - } 47(5.0 \%) \text { medial violations } \\
\text { - } 67(7.2 \%) \text { lateral violations } \\
\text { - } 823(88.8 \%) \text { correctly placed } \\
\text { - Mean threshold: } 13.6 \mathrm{~mA} \text { (range, } 3-35 \\
\text { mA) } \\
\text { - Medial breaches: } \\
\text { - Mean threshold: } 10.2 \mathrm{~mA}(2-28 \mathrm{~mA}) \\
\text { - } 8(17 \%) \text { of } 47 \text { stimulated } \leq 6 \mathrm{~mA} \\
\text { - } 23(49 \%) \text { between } 6-10 \mathrm{~mA} \\
\text { - } 16(34 \%)>10 \mathrm{~mA} \\
\text { - } 10(21.3 \%) \text { of } 47 \text { had } \geq 65 \% \text { decrease } \\
\text { from mean } \\
\text { - Only } 13(28 \%) \text { of } 47 \text { had } \leq 6 \mathrm{~mA} \text { and/or } \\
\text { } \geq 65 \% \text { decrease } \\
\text { - Lateral breaches: } \\
\text { - Mean threshold: } 15.6 \mathrm{~mA} \text { (5-35 mA) } \\
\text { - Looking at T10-T12 screws: } 7 / 282 \mathrm{medial} \\
\text { breach } \\
\text { - } 6(85.7 \%) \text { of } 7 \text { had } \leq 6 \mathrm{~mA} \text { threshold } \\
\text { and/or } \geq 65 \% \text { decrease } \\
\text { - No postoperative neurological deficits }\end{array}$ & $\begin{array}{l}\text { Based on a } \leq 6 \mathrm{~mA} \text { threshold and/or } \\
60-65 \% \text { decrease from the mean: } \\
\text { - Sensitivity }=28 \% \\
\text { - PPV }=21 \%\end{array}$ \\
\hline 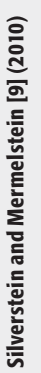 & $\begin{array}{l}\text { Prospective } \\
\text { cohort }\end{array}$ & $\begin{array}{l}\mathrm{N}=9 \\
\text { consecutive } \\
\text { patients } \\
\text { (121 screws) } \\
\text { Mean age: } 38.1 \\
\text { (range, 15-69) y } \\
\text { Male: NR }\end{array}$ & $\begin{array}{l}\text { Severe spinal } \\
\text { deformity or } \\
\text { instability }\end{array}$ & $\begin{array}{l}\text { Instrumented } \\
\text { thoracic fusion } \\
\text { and deformity } \\
\text { correction }\end{array}$ & $\begin{array}{l}\text { Triggered EMG: } \\
\text { - Screws were } \\
\text { placed in the } \\
\text { thoracic spine } \\
\text { with EMG testing } \\
\text { of the abdominus } \\
\text { rectus and } \\
\text { paraspinal } \\
\text { muscles }\end{array}$ & $\begin{array}{l}\text { Pedicle breach } \\
\text { confirmed by } \\
\text { postoperative } \\
\mathrm{CT}\end{array}$ & $\begin{array}{l}\text { - No significant breaches found } \\
\text { - No postoperative neurological deficits or } \\
\text { neurological pain in any patients in this } \\
\text { study were reported }\end{array}$ & $\begin{array}{l}\text { Based on a }<7 \mathrm{~mA} \text { threshold: } \\
\text { - Sensitivity }=100 \% \\
\text { - False-positive rate }=6 \%\end{array}$ \\
\hline
\end{tabular}

* EMG indicates electromyography; CT, computed tomography; PPV, positive predictive value; NPV, negative predictive value predictive value; NR, not reported; and N/A, not available. 
Table 2 Summary of pedicle wall breach rates, new or worsening neurological event, and diagnostic test characteristics.

\begin{tabular}{lllll}
\multicolumn{1}{c}{} & \multicolumn{2}{c}{ EMG } \\
\hline Outcomes & No. of studies & Patients (screws) & Mean, \% & Range, \% \\
\hline Pedicle wall breach rate & $8[1-8]$ & $337(2708)$ & 11.6 & $0-53.4$ \\
\hline Medial pedicle wall breach rate & $7[1,3-8]$ & $307(2513)$ & 5.6 & $0-16.5$ \\
\hline New or worsening neurological event & $8[1-8]$ & $330(2592)$ & 0 & 0 \\
\hline Sensitivity & $8[1-8]$ & $337(2708)$ & 55.0 & $0-100$ \\
\hline Specificity & $6[1-6]$ & $278(1650)$ & 82.1 & $70.1-100$ \\
\hline Positive predictive value & $5[1,4-7]$ & $291(2289)$ & 36.2 & $21-100$ \\
\hline Negative predictive value & $6[1-6]$ & $278(1650)$ & 93.9 & $75-100$ \\
\hline
\end{tabular}

Table 3 Rating of overall strength of evidence for each key question.*

Question 1: For adolescent and adult patients undergoing pedicle screw placement for thoracic deformity, what are the diagnostic characteristics (ie, sensitivity, specificity, positive predictive value, negative predictive value) of using electromyography (EMG) to identify misplacement?

\begin{tabular}{|c|c|c|c|c|c|}
\hline Outcome & Strength of evidence & Conclusions/comments & Baseline & Downgrade & Upgrade \\
\hline $\begin{array}{l}\text { Overall } \\
\text { diagnostic } \\
\text { characteristics }\end{array}$ & Low & $\begin{array}{l}\text { Mean sensitivity for identifying a pedicle wall breach was relatively low when } \\
\text { pooled across studies ( } 55.0 \%) \text {. Further, the findings were inconsistent across } \\
\text { studies ranging from 0-100\%. } \\
\text { Mean specificity was much higher at } 82.1 \% \text { across studies; with some } \\
\text { inconsistency ranging from } 70-100 \% \text {. } \\
\text { Fairly low sensitivity may lead to a high false-negative rate. It is unclear what } \\
\text { the impact of false-negatives would be since no neurological injuries were } \\
\text { identified in the studies summarized. } \\
\text { Higher specificity would suggest a fairly low false-positive rate; however, the } \\
\text { rates could be as high as 30\%. If sudden changes in treatment are required in } \\
\text { the absence of any adverse event, this could be considered a limitation of } \\
\text { such testing. }\end{array}$ & High & $\begin{array}{l}\text { Inconsistency (1) } \\
\text { Uncertainty of } \\
\text { impact of false (-) }\end{array}$ & No \\
\hline
\end{tabular}

Question 2: For adolescent and adult patients undergoing pedicle screw placement for thoracic deformity, does intraoperative EMG reduce the rate of a new or worsening neurological event or pedicle wall breach compared with no EMG?

\begin{tabular}{|c|c|c|c|c|c|}
\hline Outcome & Strength of evidence & Conclusions/comments & Baseline & Downgrade & Upgrade \\
\hline Efficacy & Insufficient & $\begin{array}{l}\text { There were no studies identified comparing patients who did and did not } \\
\text { receive EMG during pedicle screw placement to determine if EMG is more } \\
\text { effective at preventing adverse events such as a new neurological event or a } \\
\text { pedicle wall breach. }\end{array}$ & $\begin{array}{l}\text { Insuf- } \\
\text { ficient } \\
\text { level I/II } \\
\text { studies }\end{array}$ & No & No \\
\hline
\end{tabular}

* All Agency for Healthcare Research and Quality (AHRQ) "required" and "additional" domains are assessed. Only those that influence the baseline grade are listed in this table.

Baseline strength: risk of bias (including control of confounding) is accounted for in the individual article evaluations. High indicates most articles level I/II; low, most articles level III/IV; downgrade, inconsistency of results (1 or 2); indirectness of evidence (1 or 2); uncertainty about the impact of false-negatives; and no upgrades were considered. 
Fig 1 Results of literature search.

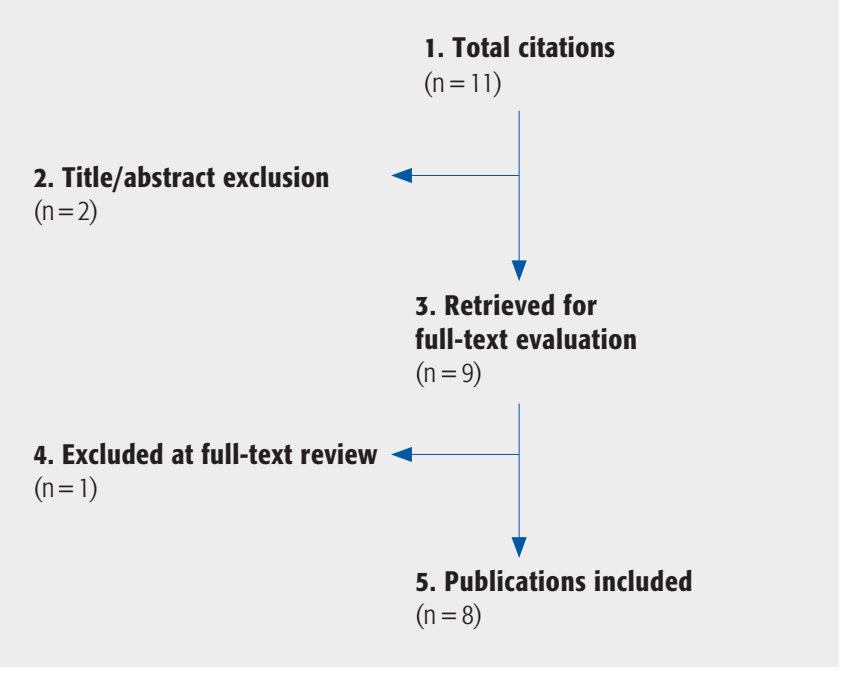

\section{REFERENCES}

1. Raynor BL, Lenke LG, Kim Y, et al (2002) Can triggered electromyograph thresholds predict safe thoracic pedicle screw placement? Spine (Phila Pa 1976); 27(18):2030-2035.

2. Finkelstein JA (2003) Letter to the editor: can triggered electromyograph thresholds predict safe thoracic pedicle screw placement? Spine; 28:960-962.

3. Donohue ML, Murtagh-Schaffer C, Basta J, et al (2008) Pulse-train stimulation for detecting medial malpositioning of thoracic pedicle screws. Spine (Phila Pa 1976); 33(12):E378385.

4. Duffy MF, Phillips JH, Knapp DR, et al (2010) Usefulness of electromyography compared to computed tomography scans in pedicle screw placement. Spine (Phila Pa 1976); 35(2):E4348.

5. Min WK, Lee HJ, Jeong WJ, et al (2011) Reliability of triggered EMG for prediction of safety during pedicle screw placement in adolescent idiopathic scoliosis surgery. Asian Spine J; 5(1):51-58.

6. Regidor I, de Blas G, Barrios C, et al (2011) Recording triggered EMG thresholds from axillary chest wall electrodes: a new refined technique for accurate upper thoracic (T2T6) pedicle screw placement. Eur Spine J; 20(10):1620-1625.

7. Rodriguez-Olaverri JC, Zimick NC, Merola A, et al (2008) Using triggered electromyographic threshold in the intercostal muscles to evaluate the accuracy of upper thoracic pedicle screw placement (T3-T6). Spine (Phila Pa 1976); 33(7):E194-197.

8. Samdani AF, Tantorski M, Cahill PJ, et al (2011) Triggered electromyography for placement of thoracic pedicle screw: is it reliable? Eur Spine J; 20(6):869-874.

9. Silverstein JW, Mermelstein LE (2010) Utilization of paraspinal muscles for triggered EMG during thoracic pedicle screw placement. $A m \mathrm{~J}$ Electroneurodiagnostic Technol; 50(1):37-49. 


\section{EDITORIAL PERSPECTIVE}

Not surprisingly this topic raised significant debate among the reviewers on a number of issues. The reviewers agreed that the authors of this systematic review have touched upon a very timely topic and did a fine job of evaluating it.

Certainly the prospect of electrodiagnostic monitoring of pedicle screws during placement has received increasing commercial interest from a number of vendors who have aggressively marketed their technologies as improving patient safety. It therefore seemed appropriate to critically evaluate their claims with the current state of literature.

The overall strength of evidence evaluating the diagnostic characteristics was low due to inconsistency between studies when comparing the following key areas:

- Variations in the technique used for EMG monitoring

- Inconsistency of identifying pedicle breach (visual and/or different types of postoperative $(T)-E M G$ was NOT used to primarily identify pedicle breaches.

- Variations in reference muscles used for monitoring

- Variations in the thresholds utilized to identify pedicle breach which can affect the measurement parameters of diagnostic efficacy such as sensitivity, specificity etc.

The editorial staff believed that we should proceed with publication of this to highlight the present day heterogeneity of EMGmonitoring methods in the literature and to focus on the issue of efficacy versus effectiveness in the application of a relative novel technique. Efficacy would require not only homogeneous methods but also data to support our key question \#2: "For adolescent and adult patients undergoing pedicle screw placement for thoracic deformity, does intraoperative EMG reduce the rate of a new or worsening neurological event or pedicle wall breach compared with no EMG?"

We found that heterogeneous methods were a clinical reality for this diagnostic technique. In other words, we had to accept some diagnostic heterogeneity as a flaw but believed we could still apply the findings to making one's own clinical decision (effectiveness). Therefore it is appropriate to ask this question and report the findings so that the clinician can look at the evidence (as poor as it may be) in one report as opposed to reading multiple individual studies.
Another hot-button topic was how to deal with the wide range of specificities in the individual studies with ranges from $70 \%$ to a full $100 \%$. The study that reported $70 \%$ [1] would suggest a false-positive rate of $30 \%$. The false-positive rate was less in other studies. Therefore, we did not report an average or an "acceptable rate" based on the literature. The reader will have to decide what is acceptable seeing that the false-positive rates reported in the literature range from $0-30 \%$.

The critical question raised was whether a systematic review study with such low strength of evidence should be published at all. It should be pointed out that as in any formal systematic review, the study questions were set apriori before we explored the literature based on what we believed were clinically relevant and important questions. Finding "no evidence" for a specific question is an important finding. For us this is the question that really needs to be answered and our systematic attempt reveals that there are no studies that have tried, despite several attempts at evaluating sensitivity and specificity in case series. The criteria to publish a systematic review therefore should not be based on overall strength of evidence after the report is completed. Clinical recommendations can even be made on reports that discover "no evidence" especially in case of novel treatment. In addition, a clinical recommendation can be made against a procedure that has high evidence to support it for well-defended reasons (eg, cost, harm, etc).

The real question that needs to be answered is whether using $E M G$ is associated with better outcomes and/or fewer adverse events than no EMG. This can only be done through comparison studies which we have discovered do not exist. That said, the authors hope that 'no findings' with respect to this question will motivate our affected specialties to attempt to answer it. Therefore, since there is no record of a systematic review attempting to answer this question in the literature, this review fills a gap, despite the strength of evidence being low. The clinician can use these findings to make their own informed decision more effectively than looking at individual articles.

Donohue ML, Murtagh-Schaffer C, Basta J, et al (2008) Pulsetrain stimulation for detecting medial malpositioning of thoracic pedicle screws. Spine (Phila Pa 1976); 33:E378-385. 